\title{
Gabrielle HOUBRE, Grandeur et décadence de Marie Isabelle, modiste, dresseuse de chevaux, femme d'affaires, etc. Paris, Perrin, 2003. 273 p.
}

\section{Caroline FORD}

\section{(2) OpenEdition}

Journals

Édition électronique

URL : https://journals.openedition.org/clio/1377

DOI : $10.4000 /$ clio. 1377

ISSN : 1777-5299

Éditeur

Belin

Édition imprimée

Date de publication : 1 novembre 2004

Pagination : 299-301

ISBN : 2-85816-755-9

ISSN : 1252-7017

Référence électronique

Caroline FORD, «Gabrielle HOUBRE, Grandeur et décadence de Marie Isabelle, modiste, dresseuse de chevaux, femme d'affaires, etc. Paris, Perrin, 2003. 273 p. », Clio. Histoire, femmes et sociétés [En ligne], 20 | 2004, mis en ligne le 06 juin 2005, consulté le 22 avril 2022. URL : http://journals.openedition.org/ clio/1377; DOI : https://doi.org/10.4000/clio.1377

Ce document a été généré automatiquement le 22 avril 2022

Tous droits réservés 


\section{Gabrielle HOUBRE, Grandeur et décadence de Marie Isabelle, modiste, dresseuse de chevaux, femme d'affaires, etc. Paris, Perrin, 2003. $273 \mathrm{p}$.}

\section{Caroline FORD}

1 Ce beau livre raconte l'histoire de Marie Isabelle, fille d'un cordonnier, au destin étonnant. À la fois "un récit de séquences biographiques» et un exercice de microhistoire dans le style de Carlo Ginzburg et d'Alain Corbin, le livre de Houbre se distingue pourtant de leurs récits en présentant l'itinéraire singulier d'une fille du peuple. Marie Isabelle a réussi comme femme de théâtre, modiste, femme d'affaires, et dresseuse de chevaux dans les cours royales de l'Europe du XIXe siècle. À travers sa vie, Gabrielle Houbre cherche à éclairer les rapports des sexes, les contraintes de genre et de classe, et la porosité du mur entre privé et public en France au XIXe siècle.

Marie Isabelle n'a pas laissé beaucoup de traces et l'auteure a donc été obligée d'opérer à la manière d'un détective, fouillant soigneusement plusieurs. Marie Isabelle loua un magasin qui vendait des accessoires de toilette féminins à Paris. Elle éprouvait une passion pour l'art aristocratique et masculin de l'équitation. Au bout d'un certain temps, elle créa une nouvelle méthode de dressage des chevaux de troupe par le surfaix-cavalier dont elle était extrêmement fière. En 1852 elle partit toute seule pour la Russie, s'arrêtant à Vienne. En Russie, elle donna des leçons d'équitation. Le Tsar Nicolas Ier luimême fut conquis par sa méthode de surfaix-cavalier et lui demanda de l'enseigner au régiment impérial mais elle fut obligée de quitter cette ville en 1854, à la veille de la guerre de Crimée. Après son retour en France, le Ministère de la Guerre lui confia la tâche d'enseigner sa méthode de dressage à la prestigieuse École de cavalerie de Saumur. L'hostilité des militaires, qui l'accusaient d'être «trop femme » (ou de ne l'être pas assez) explique son échec dans un milieu masculin et parfois misogyne. Elle 
essaya de se défendre en attaquant à son tour ses adversaires, mais ses efforts demeurèrent vains et elle fut renvoyée à Paris. Les années qui séparent son échec à l'École de Saumur, de sa mort en 1875, furent celles du déclin.

3 La microhistoire est un genre qui permet à l'historienne d'éclairer le passé à plusieurs échelles. Elle montre les tensions, contradictions, et courants d'idées dans la vie privée comme dans la vie publique. Souvent les historiens cherchent un personnage "représentatif" ou un incident frappant. Marie Isabelle n'est pas pourtant une "everywoman", un personnage ordinaire. Elle aurait pu être une héroïne de La Comédie Humaine, en transgressant les barrières de classe (et de sexe) après une révolution qui avait aboli une société basée sur les privilèges et les ordres. Comment a-t-elle réussi dans la société du Second Empire, et pourquoi a-t-elle échoué finalement? Qu'est-ce que ce livre révèle du monde de l'armée française au moment de la guerre de Crimée, et quels étaient les rôles respectifs du spectacle, du commerce et du genre dans l'histoire de ses méthodes de dressage? Ce livre donne des indications fort intéressantes sur chacune de ces questions, mais ses réponses restent parfois incomplètes.

4 Ce n'est pas seulement la force de sa personnalité qui a permis à Marie Isabelle d'entrer dans les coulisses de la politique et de la haute société française, autrichienne et russe. Elle comptait sur sa capacité à s'auto-inventer («self-fashioning») et sur les réseaux masculins et surtout féminins qu'elle développa d'abord au théâtre, et ensuite dans le commerce. Gabrielle Houbre indique que le théâtre offrait «l'une des rares échappatoires au prolétariat » (p. 86). Deux femmes, l'illustre comédienne Rachel et la comtesse Olga de Rochefort, l'ont présentée à la haute société et au Ministère de la Guerre. L'auteure montre bien les possibilités et les limites de l'ascension sociale pour une femme du peuple dans la France du XIXe siècle. L'échec de Marie Isabelle à l'École de Saumur n'est guère surprenant, mais les raisons pour lesquelles le Ministère l'a engagée et le fait qu'elle fut accueillie par les cours impériales de l'Europe, restent toujours mystérieuses. Y-a-t-il une explication à chercher aussi dans le conjoncture politique, dans la "macrohistoire" des relations internationales, dans l'histoire de l'armée en général, et de la cavalerie en particulier? Par exemple, une note biographique, fort critique, publiée pendant la guerre de Crimée, suggérait que le prince de Menschikoff avait envoyé Marie Isabelle en France après son séjour en Russie pour désorganiser la cavalerie qu'il redoute à juste titre. Il est peu probable qu'elle ait été un "agent" soumis ou insoumis de la Russie. Mais il se peut bien que le Ministère, conscient de la dégradation des relations entre les deux pays, ait voulu recueillir des informations sur la cour russe et sur ce qu'elle avait fait en Russie. Pour répondre à ces questions il serait nécessaire de suivre des pistes dans les archives et les bibliothèques de Londres, Vienne et Saint Pétersbourg, ce qui souligne les problèmes que pose la microhistoire dans une société où la mobilité des individus s'accroit.

Gabrielle Houbre évoque à la fois une société aristocratique en voie de disparition et les débuts d'une société où monte, à la fin du siècle, une culture commerciale. L'histoire de Marie Isabelle nous montre les possibilités dont la «femme nouvelle» de la Belle Époque disposait mais aussi l'importance toujours persistante des structures traditionnelles de la société française. Ni victime ni héroïne, Marie Isabelle portait en elle-même ces deux mondes. 